\title{
Monitoring of Pesticide Residues in Commonly Used Fruits in Hyderabad Region, Pakistan
}

\author{
Yawar Latif, Syed Tufail Hussain Sherazi*, Muhammad Iqbal Bhanger \\ National Centre of Excellence in Analytical Chemistry, University of Sindh, Jamshoro, Pakistan \\ E-mail: tufail.sherazi@yahoo.com \\ Received November 2, 2011; revised December 5, 2011; accepted December 12, 2011
}

\begin{abstract}
A market based survey was carried out to evaluate the level of 26 pesticides in some commonly used fruits in Hyderabad region, Pakistan. Gas chromatography coupled with micro electron capture detector was used to assess the levels of pesticide residues. Gas chromatography-mass spectrometry (GC-MS) was also applied for the confirmation of results. Out of total 131 analyzed samples, $53(40 \%)$ were found contaminated with pesticide residues while only $3(2 \%)$ samples were exceeded the MRLs of some pesticides. Chlorpyrifos and dieldrin were detected in almost all analyzed samples. Residues of chlorpyrifos $(1256 \mu \mathrm{g} / \mathrm{kg})$ and endosulfan sulfate $(1236 \mu \mathrm{g} / \mathrm{kg})$ were found higher in orange and apple samples, respectively. The findings of this study provided important data about contamination of pesticide residue in some fruits sold in Hyderabad, Pakistan, and recommended that monitoring studies should be expanded to other fruits grown in different agro climatic regions, which may serve as basis for future policy about the standards and quality control of pesticides.
\end{abstract}

Keywords: Market Survey, Fruit Samples, Pesticides Residues, GC- $\mu$ ECD

\section{Introduction}

No doubt, the use of pesticides has resulted to increase agricultural production worldwide but some persistent pesticide residues have great potential of adverse impact on the environment and human health. Application of pesticides in modern agriculture has boosted farm productivity [1]. Vegetables and fruits are commonly used everywhere to meet the requirement of balance diet and good health [2]. Pesticides contamination is a worldwide public health concern and also a main international trade problem [3]. Several pesticides are noxious substances and can persistent in the environment for a long time. Therefore, health point of view it is necessary to control the application of pesticides on crops [4,5]. On the other hand, different types of new pesticides have been introduced in market during last few decades to enhance better yield and quality of agricultural products [6]. However, levels of pesticides should be controlled at optimum point due to their relative toxicity to the environment and human health [7]. Thus, maximum residue levels (MRLs) for pesticides have established worldwide, which usually guide to manage the quantity of pesticides in foodstuffs.

Residues resulting from the inappropriate use of pesti- cides on fruits have turn out to be most important concern in many countries, as well as in Pakistan. Agriculture sector is playing important role to support the economy of Pakistan. Furthermore, recent production of fruits in Pakistan is almost 4.7 million tons per anum and some fruits are also exported to other countries. Contribution of food stuff is about $13.2 \%$ in entire exports together with fruits [8]. Use of pesticides in Pakistan is not well controlled as compare to the developed countries due to ineffective legislation, lack of awareness and inappropriate pesticide management. Applications of chemicals to manage pests are being adept in Pakistan since decades; but, agro chemicals have acquired in 1954 with 254 metric tons of formulation [9]. The reliance on pesticides is apparent from the growing trend in its utilization from 665 metric ton in 1980 to 45,680 metric ton in 1999 [10], and reached to 25000 metric ton in 2006 [11]. No statistics data are available on the levels of pesticide residues in fruits sold in rural and urban markets of Hyderabad region, Pakistan, which is the eighth biggest city of the state and second largest city of the Sindh province (on the bases of population). Hyderabad city is situated on the east bank of the river Indus and about $150 \mathrm{~km}$ away from Karachi city. District Hyderabad contains huge urban and rural areas. The literacy rate in rural area as compare 
to the urban areas is very low, which is the main reason of improper use of pesticides. They are completely unaware to the approach of integrated pest management (IPM). Additionally, the use of incorrect or high dosage of pesticides leads to the contamination of pesticides in their agricultural products which may be health risk to the consumer. Thus, the monitoring of pesticide residues in fruits has become ever more essential requirement for consumers, producers and institutions concerned with standards and quality control management [12]. A market based survey was conducted to investigate the possible contamination of fruits sold in the major markets of Hyderabad region of Pakistan. The motive for the selection of Hyderabad district is that it is one of major commercial centre for the agricultural produce especially fruits, cotton, wheat, and vegetables.

\section{Materials and Methods}

\subsection{Sample Collection and Preparation}

For the evaluation of pesticide residues, a total of 131 samples of some fruits including apples, grapes and oranges were collected during the period of October 2010 -April 2011 from three different main fruit markets located in urban areas of Hyderabad region, Sindh, Pakistan. The size of the sample of each fruit was between 2 $3 \mathrm{~kg} .17$ samples of apple, 12 samples of grapes and 13 samples of oranges were purchased from the fruit market No.1. Similarly 14 samples of apple, 14 samples of grapes and 11 samples of orange were obtained from the fruit market No. 2. While from the fruit market No. 3, 16 samples of apple, 15 samples of grapes and 19 samples of oranges were purchased in different dates. Each sample of fruit was chopped and $200 \mathrm{~g}$ portion get homogenized and kept in glass stopper bottle and stored under freezing temperature until extraction.

\subsection{Extraction and Cleanup}

An aliquot from each sample (10 g) was weighed and extracted twice with $20 \mathrm{ml}$ ethyl acetate. Extracts were kept in a sonicator for $2 \mathrm{~min}$ at $40^{\circ} \mathrm{C} \pm 2^{\circ} \mathrm{C}$. After sonication, extracts were filtered through a filter paper with the assistance of suction pump. Residues were washed with ethyl acetate $(10 \mathrm{ml})$ and extracts were shifted into a separatory funnel. The aqueous phase was discarded while organic phase was passed through anhydrous sodium sulfate and evaporated to dryness in a rotary evaporator. Residues were dissolved in ethyl acetate and cleaned-up on SPE column containing $1 \mathrm{~g}$ of $\mathrm{C} 18$ preconditioned with acetonitrile $(3 \mathrm{ml})$ and water $(5 \mathrm{ml})$. The extracted residues were put on the top of column and eluted twice with $5 \mathrm{ml}$ of hexane-ethyl acetate $(1: 1, \mathrm{v} / \mathrm{v})$. Eluate was evaporated on a rotary evaporator and dissolved in ethyl acetate and transferred to a glass tube and concentrated under a gentle stream of air to a suitable volume. An aliquot of the last extract was examined by $\mathrm{GC}-\mu \mathrm{ECD}$ and identification of the residues was carried by the standards and also by GC-MS.

\subsection{Gas Chromatographic Analysis}

Analysis of pesticide residues was carried out on an Agilent (CA, USA) model 7890 A GC system coupled with micro Electron Capture Detector ( $\mu \mathrm{ECD})$, in combination with automatic split-splitless injector model Agilent 7683 B and 7683 Agilent autosampler. For the separation of analytes a HP-5 glass capillary column (30 $\mathrm{m} \times 0.32 \mathrm{~mm} \times$ i.d., $0.25 \mu \mathrm{m}$ film thickness) supplied by Agilent Technologies, was installed. Injector and detector temperatures were set up to $250^{\circ} \mathrm{C}$ and $310^{\circ} \mathrm{C}$ respectively. Temperature for column was programmed as; the starting temperature was $70^{\circ} \mathrm{C}$ for $0 \mathrm{~min}$, after that raised at a rate of $30^{\circ} \mathrm{C} / \mathrm{min}$ to $210^{\circ} \mathrm{C}$ and seized for $2 \mathrm{~min}$, then from $210^{\circ} \mathrm{C}$ to $250^{\circ} \mathrm{C}$ at a rate of $25^{\circ} \mathrm{C} / \mathrm{min}$ with held for $2 \mathrm{~min}$, then increased up to $290^{\circ} \mathrm{C}$ with the rate of $30^{\circ} \mathrm{C}$ /min and lastly held for $5 \mathrm{~min}$. Nitrogen (purity 99.99\%) was used as carrier gas with flowing at $1.2 \mathrm{ml} / \mathrm{min}$.

For the confirmation of detected residues an Agilent Technologies $6890 \mathrm{~N}$ network GC system equipped with a 5975 inert MSD with the combination of Electron Impact (EI) as source for ionization and Agilent 7683 automatic split-splitless injector, was employed. The temperatures of ionization source and quadrupole were kept at $230^{\circ} \mathrm{C}$ and $150^{\circ} \mathrm{C}$, respectively. For identification, the major ions $(\mathrm{m} / \mathrm{z})$ and retention times $\left(\mathrm{t}_{\mathrm{R}}\right)$ both were considered (Table 1).

\section{Result and Discussion}

Maximum residue levels (MRLs) of the selected pesticides in different fruits were shown in (Table 2). For allethrin, bromacil, bromophos-methyl and dialifos no MRLs established so far. Data given in Table 3 shows that 42 fruit samples including apple, grape and orange, collected from fruit market No.1, were evaluated for 26 pesticides. In analyzed samples, level of chlorpyrifos was found to be exceeded MRL with the highest concentration of $1256 \mu \mathrm{g} / \mathrm{kg}$ in apple, followed by disulfoton with concentration of $398 \mu \mathrm{g} / \mathrm{kg}$ in orange, which was within the MRL. Dieldrin was detected in 2 samples of apple and 1 sample of orange. Maximum concentration (37 $\mu \mathrm{g} / \mathrm{kg}$ ) was observed in apple. Similarly, the fungicide, triadimefon was found only in 2 samples of apple (114 $\mu \mathrm{g} / \mathrm{kg}$ ), which was below the MRL. Residues of insecti- 
cides, parathion (in 2 samples) and disulfoton (in 1 sample) were also detected in the orange samples. Maximum levels of both pesticides were detected as $311 \mu \mathrm{g} / \mathrm{kg}$ and $398 \mu \mathrm{g} / \mathrm{kg}$, respectively.

The levels of pesticides in 39 samples of fruits which were collected from the fruit market No. 2 are shown in Table 4. Similar to the results of market No. 1, chlorpyrifos was detected in higher concentration $(1119 \mu \mathrm{g} / \mathrm{kg})$ in orange and crossed the MRL, followed by endosulfan sulfate with the concentration of $307 \mu \mathrm{g} / \mathrm{kg}$ in apple, and

Table 1. Pesticide names, chemical active group, usage, molecular weight, retention times and selected MS main ions (m/z).

\begin{tabular}{|c|c|c|c|c|c|}
\hline \multirow[t]{2}{*}{ Pesticides } & \multirow[t]{2}{*}{ Group } & \multirow[t]{2}{*}{ Use } & \multirow[t]{2}{*}{ MW } & \multirow[t]{2}{*}{$t_{R}, \min$} & \multirow{2}{*}{$\frac{\text { MS }}{\text { Selected ions }(\mathrm{m} / \mathrm{z})}$} \\
\hline & & & & & \\
\hline Phosdrin & Organophosphate & Insecticide & 224 & 5.08 & $109,127,192$ \\
\hline$\alpha-\mathrm{HCH}$ & Organochlorine & Insecticide & 288 & 6.68 & $111,181,219$ \\
\hline Dimethoate & Organophosphate & Insecticide & 229 & 6.82 & 87,125 \\
\hline$\beta$-HCH & Organochlorine & Insecticide & 288 & 7.00 & $111,181,219$ \\
\hline$\gamma-\mathrm{HCH}$ & Organochlorine & Insecticide & 288 & 7.10 & $111,181,219$ \\
\hline Disulfoton & Organophosphate & Insecticide & 274 & 7.30 & 109,157 \\
\hline Chlorpyrifos Methyl & Organophosphate & Insecticide & 322 & 7.65 & $208,288,286$ \\
\hline Propanil & Acylanilide & Herbicide & 218 & 7.69 & 161,217 \\
\hline Metribuzin & Triazine & Herbicide & 214 & 7.74 & $198,144,182$ \\
\hline Parathion Methyl & Organophosphate & Insecticide & 263 & 7.85 & $109,263,125$ \\
\hline Heptachlor & Organochlorine & Insecticide & 389 & 7.99 & 100,272 \\
\hline Bromacil & Uracils & Herbicide & 261 & 8.18 & $207,205,231$ \\
\hline Malathion & Organophosphate & Insecticide & 330 & 8.24 & $127,158,173$ \\
\hline Parathion & Organophosphate & Insecticide & 291 & 8.39 & 125,291 \\
\hline Aldrin & Organochlorine & Insecticide & 364 & 8.40 & $293,263,221$ \\
\hline Triadimefon & Triazole & Fungicide & 293 & 8.44 & $208,128,181$ \\
\hline Bromophos Methyl & Organophosphate & Insecticide & 366 & 8.65 & 331,125 \\
\hline Allethrin & Pyrethroid & Insecticide & 302 & 8.86 & $91,123,136$ \\
\hline Tolyfluanid & Phenylsulfamide & Fungicide & 347 & 8.89 & $137,238,106,63$ \\
\hline Captan & Phthalimide & Fungicide & 300 & 8.98 & $79,264,299$ \\
\hline Bromophos Ethyl & Organophosphate & Insecticide & 394 & 9.19 & $303,359,331$ \\
\hline$\alpha$-Endosulfan & Organochlorine & Insecticide & 406 & 9.44 & $195,241,339$ \\
\hline Dieldrin & Organochlorine & Insecticide & 378 & 9.83 & 277,345 \\
\hline$\beta$-Endosulfan & Organochlorine & Insecticide & 406 & 10.37 & $195,241,339$ \\
\hline DDT & Organochlorine & Insecticide & 354 & 11.00 & $165,235,237$ \\
\hline Endosulfan sulfate & Organochlorine & Insecticide & 422 & 11.01 & $272,387,420$ \\
\hline Dialifos & Organophosphate & Insecticide & 393 & 12.73 & $76,181,357$ \\
\hline
\end{tabular}


Table 2. Maximum residue limits (MRLs) of targeted pesticides.

\begin{tabular}{|c|c|c|c|}
\hline \multirow[t]{2}{*}{ Pesticides } & \multicolumn{3}{|c|}{ MRLs, $(\mu g / \mathbf{k g})^{a}$} \\
\hline & Apple & Grape & Orange \\
\hline Aldrin & 50 & 100 & 50 \\
\hline Allethrin & $\mathrm{NE}^{*}$ & $\mathrm{NE}$ & NE \\
\hline Bromacil & $\mathrm{NE}$ & $\mathrm{NE}$ & $\mathrm{NE}$ \\
\hline Bromophos Methyl & NE & $\mathrm{NE}$ & NE \\
\hline Bromophos Ethyl & 50 & 50 & 50 \\
\hline Captan & 15000 & 25000 & 15000 \\
\hline Chlorpyrifos & 1000 & 500 & 1000 \\
\hline Chlorpyrifos Methyl & 500 & 200 & 500 \\
\hline Dialifos & $\mathrm{NE}$ & NE & $\mathrm{NE}$ \\
\hline Dichlorvos & 100 & 100 & 100 \\
\hline Dieldrin & 50 & 100 & 50 \\
\hline Dimethoate & 2000 & 2000 & 5000 \\
\hline Disulfoton & 500 & 500 & 500 \\
\hline$\alpha$-Endosulfan & 2000 & 2000 & 2000 \\
\hline$\beta$-Endosulfan & 2000 & 2000 & 2000 \\
\hline Endosulfan sulfate & 2000 & 2000 & 2000 \\
\hline$\alpha-\mathrm{HCH}$ & 3000 & 3000 & 3000 \\
\hline$\beta-\mathrm{HCH}$ & 3000 & 3000 & 3000 \\
\hline$\gamma-\mathrm{HCH}$ & 3000 & 3000 & 3000 \\
\hline$\delta$ - $\mathrm{HCH}$ & 3000 & 3000 & 3000 \\
\hline Heptachlor & 10 & 10 & 10 \\
\hline Malathion & 20 & 20 & 20 \\
\hline Metribuzin & 100 & 100 & 100 \\
\hline Parathion Methyl & 200 & 500 & 200 \\
\hline Parathion & 500 & 500 & 500 \\
\hline Propanil & 100 & 100 & 100 \\
\hline Tolyfluanid & 5000 & 3000 & 50 \\
\hline Triadimefon & 300 & 500 & 100 \\
\hline DDT & 1000 & 1000 & 1000 \\
\hline Phosdrin & 10 & 10 & 10 \\
\hline
\end{tabular}

${ }^{*} \mathrm{NE}=$ Not established, ${ }^{\mathrm{a}}$ According to Codex Alimentarius Commission and www.pmfai.org/stat.htm. 
Table 3. Pesticide residue levels $(\mu \mathrm{g} / \mathrm{kg})$ found in fruits collected from fruit market No. 1 .

\begin{tabular}{|c|c|c|c|c|c|c|}
\hline \multirow{3}{*}{ Pesticides } & \multicolumn{6}{|c|}{ Pesticide levels in $(\mu \mathrm{g} / \mathrm{kg})$} \\
\hline & \multicolumn{2}{|c|}{ Apple } & \multicolumn{2}{|c|}{ Grape } & \multicolumn{2}{|c|}{ Orange } \\
\hline & Contaminated & $\operatorname{Min}-\operatorname{Max}(\mu \mathrm{g} / \mathrm{kg})$ & Contaminated & $\operatorname{Min}-\operatorname{Max}(\mu \mathrm{g} / \mathrm{kg})$ & Contaminated & $\operatorname{Min}-\operatorname{Max}(\mu \mathrm{g} / \mathrm{kg})$ \\
\hline Chlorpyrifos & 03 & $231-1256^{\mathrm{a}}$ & 01 & 205 & 02 & $145-243$ \\
\hline Parathion & - & - & - & - & 02 & $102-311$ \\
\hline Dieldrin & 02 & $21-37$ & - & - & 01 & 13 \\
\hline $\begin{array}{l}\text { Endosulfan } \\
\text { sulfate }\end{array}$ & 01 & 134 & 01 & 81 & 01 & 213 \\
\hline Triadimefon & 02 & $37-114$ & - & - & - & - \\
\hline Disulfoton & - & - & - & - & 01 & 398 \\
\hline
\end{tabular}

${ }^{a}$ Exceed the MRL.

Table 4. Pesticide residue levels $(\mu \mathrm{g} / \mathrm{kg})$ found in fruits collected from fruit market No. 2 .

\begin{tabular}{|c|c|c|c|c|c|c|}
\hline \multirow{3}{*}{ Pesticides } & \multicolumn{6}{|c|}{ Pesticide levels in $(\mu \mathrm{g} / \mathrm{kg})$} \\
\hline & \multicolumn{2}{|c|}{ Apple } & \multicolumn{2}{|c|}{ Grape } & \multicolumn{2}{|c|}{ Orange } \\
\hline & Contaminated & $\operatorname{Min}-\operatorname{Max}(\mu \mathrm{g} / \mathrm{kg})$ & Contaminated & $\operatorname{Min}-\operatorname{Max}(\mu \mathrm{g} / \mathrm{kg})$ & Contaminated & $\operatorname{Min}-M a x(\mu g / k g)$ \\
\hline Chlorpyrifos & 02 & $167-684$ & 02 & $05-401$ & 02 & $253-1119^{\mathrm{a}}$ \\
\hline Parathion & 01 & 73 & - & - & - & - \\
\hline Dieldrin & 02 & $11-34$ & - & - & 02 & $23-41$ \\
\hline Endosulfan sulfate & 02 & $14-307$ & 01 & 15 & 01 & 117 \\
\hline Triadimefon & 01 & 19 & - & - & 01 & 34 \\
\hline
\end{tabular}

${ }^{\mathrm{a}}$ Exceed the MRL.

also found in one sample of orange with concentration of $117 \mu \mathrm{g} / \mathrm{kg}$. Only one sample of apple was contaminated with parathion with the level of $73 \mu \mathrm{g} / \mathrm{kg}$. While, dieldrin was found in 2 samples of apple and 2 samples of orange of the market number 2 with the concentrations of 34 $\mu \mathrm{g} / \mathrm{kg}$ and $41 \mu \mathrm{g} / \mathrm{kg}$, respectively, under MRL. The results also showed that, in 1 samples of apple and 1 sample of orange residues of the fungicide triadimefon were detected with the concentrations of $19 \mu \mathrm{g} / \mathrm{kg}$ and 34 $\mu \mathrm{g} / \mathrm{kg}$, respectively.

The data given in Table 5 demonstrated pesticide residue levels $(\mu \mathrm{g} / \mathrm{kg})$ found in fruits collected from fruit market No. 3 of Hyderabad region. 50 fruit samples were collected from this fruit market. In these samples, endosulfan sulfate and chlorpyrifos were found to in greater concentration of $1236 \mu \mathrm{g} / \mathrm{kg}$ and $1091 \mu \mathrm{g} / \mathrm{kg}$ in orange and apple, respectively and chlorpyrifos was exceeded the MRL. Chlorpyrifos also found in 2 samples of grapes and 2 samples of orange with the level of $172 \mu \mathrm{g} / \mathrm{kg}$ and $882 \mu \mathrm{g} / \mathrm{kg}$, respectively. The samples of apple and grapes were also found to be contaminated with the residues of insecticide endosulfan sulfate with concentrations of 210 $\mu \mathrm{g} / \mathrm{kg}$ in apple and $55 \mu \mathrm{g} / \mathrm{kg}$ in grapes. The insecticide parathion was the only pesticide found in orange fruit of the main fruit market number 3 with concentration of 21 $\mu \mathrm{g} / \mathrm{kg}$. Dieldrin was the another insecticide found in 2 samples of apple with maximum concentration of 30 $\mu \mathrm{g} / \mathrm{kg}$ and in 2 samples of orange with the concentration of $41 \mu \mathrm{g} / \mathrm{kg}$, which are under their MRLs. Residues of disulfoton were detected in 1 sample of apple with concentration of $46 \mu \mathrm{g} / \mathrm{kg}$ and in 1 sample of orange with the concentration of $31 \mu \mathrm{g} / \mathrm{kg}$.

In this study, the residues of targeted pesticides were evaluated in 131 samples of apple, grapes and orange obtained from the three fruit markets i.e. towns Latifabad (market number 1), Qasimabad (market number 2) and main Hyderabad city (market number 3 ). In the analyzed samples, 7 pesticides belonging to the different chemical groups (organophosphates, organochlorines and triazole) with different properties (6 insecticides and 1 fungicide) were detected. Total number of samples collected from each market, identified classes of pesticides and numbers of samples above to the MRLs are illustrated in Table 6. Out of total 131 samples analyzed, 53 samples (40\%) 
Table 5. Pesticide residue levels $(\mu \mathrm{g} / \mathrm{kg})$ found in fruits collected from fruit market No. 3 .

\begin{tabular}{|c|c|c|c|c|c|c|}
\hline \multirow{3}{*}{ Pesticides } & \multicolumn{6}{|c|}{ Pesticide levels in $(\mu \mathrm{g} / \mathrm{kg})$} \\
\hline & \multicolumn{2}{|c|}{ Apple } & \multicolumn{2}{|c|}{ Grape } & \multicolumn{2}{|c|}{ Orange } \\
\hline & Contaminated & $\operatorname{Min}-\operatorname{Max}(\mu \mathrm{g} / \mathrm{kg})$ & Contaminated & $\operatorname{Min}-\operatorname{Max}(\mu \mathrm{g} / \mathrm{kg})$ & Contaminated & $\operatorname{Min}-\operatorname{Max}(\mu g / k g)$ \\
\hline Chlorpyrifos & 03 & $328-1091^{a}$ & 02 & $26-172$ & 02 & $345-882$ \\
\hline Parathion & - & - & - & - & 01 & 21 \\
\hline Dieldrin & 02 & $14-30$ & - & - & 02 & $26-41$ \\
\hline Endosulfan sulfate & 01 & 210 & 01 & 55 & 03 & $13-1236$ \\
\hline Disulfoton & 01 & 46 & - & - & 01 & 31 \\
\hline
\end{tabular}

${ }^{\mathrm{a}}$ Exceed the MRL.

Table 6. Total number of samples collected from all markets, frequencies of pesticides found and number of samples exceeds MRLs.

\begin{tabular}{|c|c|c|c|c|c|}
\hline Fruits & Total samples & Pesticide type & Pesticide Name & Frequency & Above MRLs \\
\hline \multirow{5}{*}{ Apple } & \multirow{5}{*}{47} & \multirow[t]{2}{*}{ Insecticide } & Chlorpyrifos & 08 & 02 \\
\hline & & & Dieldrin & 06 & - \\
\hline & & \multirow[t]{3}{*}{ Fungicide } & Parathion & 01 & - \\
\hline & & & Disulfoton & 01 & - \\
\hline & & & Triadimefon & 03 & \\
\hline Grape & 41 & Insecticide & Endosulfan sulfate & 03 & - \\
\hline \multirow{6}{*}{ Orange } & \multirow{6}{*}{43} & \multirow[t]{4}{*}{ Insecticide } & Chlorpyrifos & 06 & 01 \\
\hline & & & Dieldrin & 05 & - \\
\hline & & & Endosulfan sulfate & 05 & - \\
\hline & & & Parathion & 03 & - \\
\hline & & \multirow[t]{2}{*}{ Fungicide } & Disulfoton & 02 & - \\
\hline & & & Triadimefon & 01 & - \\
\hline
\end{tabular}

contained detectable amount of pesticide residues, while in remaining 78 samples $(60 \%)$ no pesticide residues were not detected. Out of which 3 samples $(6 \%)$ were exceeded the MRLs, whereas 50 samples (94\%) contained pesticide residues below the MRLs. Most frequently detected pesticide was chlorpyrifos (insecticide) found in 19 samples (36\%), followed by the endosulfan sulfate (insecticide) in 12 samples (23\%) and dieldrin (insecticide) in 11 samples $(21 \%)$. According to the results, level of chlorpyrifos was exceeded from the MRL in 2 samples. Out of 43, 22 samples of oranges (51\%) were found to be contaminated with pesticides with 1 sample $(2 \%)$ above the MRL. Similarly, on the bases of pesticides contamination, apple was found to be second fruit, as 23 out of 47 samples (49\%) were found to be contaminated and 2 samples (4\%) exceeded the MRLs. Grapes was the commodity contained lowest number of pesticides contamination i.e. 8 out of total 41 samples (36\%) found to be adulterated. No any contaminated sample of grapes was found above to be above MRL. The results of the study also shows that pesticides which was detected in greater amount was chlorpyrifos with the concentration of $1256 \mu \mathrm{g} / \mathrm{kg}$ (apple), followed by endosulfan sulfate with level of $1236 \mu \mathrm{g} / \mathrm{kg}$ (orange), while the concentrations of disulfoton, parathion, triadimefon and dieldrin were $398 \mu \mathrm{g} / \mathrm{kg}$ (orange), $311 \mu \mathrm{g} / \mathrm{kg}$ (orange), $114 \mu \mathrm{g} / \mathrm{kg}$ (apple) and $41 \mu \mathrm{g} / \mathrm{kg}$ (orange), respectively. Frequent occurrence of pesticide residues in fruits may be due to the lack of awareness of the growers about the dosage, right ways of application and the suitable interval between harvesting and pesticide treatment. The carelessness or non-availability of correct guidance concerning the pesticide application may be another reason for pesticide residues in the fruit samples. These contaminated fruits are potential health risks to the consumers. In terms of pesticide residues some of the samples contained more than one residue. The rationale for that might be that fruits cultivated in greenhouse conditions are very much sensitive to pests and be required to for consecutive applications of pesticide treatments, leaving in result higher amount of residues that abided and defended from quick degradation by direct sunbeams. In Hyderabad region, the misuse or overuse of pesticides and casual combinations of pesticides of different groups 
without any prior guidance and knowledge are become serious problems. The improper use of pesticides shows the way to terrific financial losses and dangers to human health. Some studies have been already reported regarding the pesticide residues in different fruits at different periods $[13,19]$. Their data on fruits shows that the levels of pesticide residues were greater as compare to present study. Taken as a whole, consumption of pesticides in the country was decreased from 41406 tons in 2003-2004 to 20394 tons in the period of 2006-2007. Decline in number of samples not exceeding MRLs may be associated with decrease in quantity of pesticide consumption.

The outcomes of the present study authenticate the existence of pesticides such as chlorpyrifos, dieldrin, endosulfan sulfate, parathion, disulfoton and triadimefon in fruit samples which were applied in pre-harvest treatment. To avoid adverse effects on public health it is a necessity to set up control measures so as to make sure that each pesticide should be below MRLs in the fruits to be marketed. The study has presented significant information regarding pesticide residues contamination on fruits from Hyderabad region. On the bases of achieved results, it is recommended that regular evaluation of pesticide residue should be carried out on each fruit for the planning and future policy about the formulation of standards and quality control of pesticides.

\section{Acknowledgements}

Authors would like to thank National Centre of Excellence in Analytical Chemistry, University of Sindh Jamshoro Pakistan, for the financial support to carry out the present research work.

\section{References}

[1] W. J. Krol, T. L. Arsenault, H. M. Pylypiw, et al., "Reduction of Pesticide Residues on Produce by Rinsing," Journal of Agriculture and Food Chemistry, Vol. 48, No. 10, 2000, pp. 4666-4670. doi:10.1021/jf0002894

[2] C. K. Bempah and A. K. Donkor, "Pesticide Residues in Fruits at the Market Level in Accra Metropolis, Ghana, a Preliminary Study," Journal of Environmental Monitoring and Assessment, Vol. 175, No. 1-4, 2011, pp. 551-561. doi:10.1007/s10661-010-1550-0

[3] K. Beena and T. S. Kathpal, "Monitoring of Pesticide Residues in Vegetarian Diet," Journal of Environmental Monitoring and Assessment, Vol. 151, No. 1-4, 2009, pp. 19-26. doi:10.1007/s10661-008-0210-0

[4] S. Freidberg, "Cleaning up down South: Supermarkets, Ethical Trade and African Horticulture," Social and Cultural Geography, Vol. 4, No. 1, 2003, pp. 27-43. doi:10.1080/1464936032000049298

[5] J. Pretty and R. Hine, "Pesticide Use and the Environ- ment," In: J. Pretty, Ed., The Pesticide Detox: Towards a More Sustainable Agriculture, Earthscan, London, 2005.

[6] A. Adeyeye and O. Osibanjo, "Residues of Organochlorine Pesticides in Fruits, Vegetables and Tubers from Nigerian Markets," The Science of Total Environment, Vol. 231, No. 2-3, 1999, pp. 227-233.

[7] Y. F. Jiang, X. T. Wang, Y. Jia, et al., "Occurrence, Distribution and Possible Sources of Organochlorine Pesticides in Agricultural Soil of Shanghai, China," Journal of Hazardous Material, Vol. 170, No. 2-3, 2009, pp. 989997. doi:10.1016/j.jhazmat.2009.05.082

[8] Anonymous, "Economic Survey of Pakistan," Finance Division, Government of Pakistan, Islamabad, 2008.

[9] M. I. Tariq, S. Afzal, I. Hussain, et al., "Pesticides Exposure in Pakistan: A Review," Environmental International, Vol. 33, No. 8, 2007, pp. 1107-1122. doi:10.1016/j.envint.2007.07.012

[10] Anonymous, "Plant Protection Department," Ministry of Food, Agriculture and Livestock (MINFAL), Karachi, 2000.

[11] Anonymous, "Economic Survey of Pakistan," Finance Division, Government of Pakistan, Islamabad, 2007.

[12] K. Beena, V. K. Madan and T. S. Kathpal, "Monitoring of Pesticide Residues in Fruits," Journal of Environmental Monitoring and Assessment, Vol. 123, No. 1-3, 2006, pp. 407-412. doi:10.1007/s10661-006-1493-7

[13] S. Tahir, T. Anwar, I. Ahmed, et al., "Determination of Pesticide Residues in Fruits and Vegetables in Islamabad Market," Journal of Environmental Biology, Vol. 22, No. 1, 2001, pp. 71-74.

[14] I. Ahmad, "Pesticide Residues in Fortified Water, Soil, Food, Fruits and Vegetable Samples in Pakistan," Journal of Experimental Zoology India, Vol. 7, No. 1, 2004, pp. 67-72.

[15] T. Anwar, S. Tahir, I. Ahmad, et al., "Pesticide Residues in Vegetables Collected from Markets of Mardan (NWFP), Lahore and Faisalabad (Punjab), Pakistan," Bulletin of Pure and Applied Sciences, Vol. 23A, No. 1, 2004, pp. 11-19.

[16] S. Hussain, T. Masud and K. Ahad, "Determination of Pesticides Residues in Selected Varieties of Mango," $\mathrm{Pa}$ kistan Journal of Nutrition, Vol. 1, No. 1, 2004, pp. 41-42.

[17] Z. Parveen, M. I. Khuhro and N. Rafiq, "Monitoring of Pesticide Residues in Vegetables (2000-2003) in Karachi, Pakistan," Bulletin of Contamination Toxicology, Vol. 74, No. 1, 2005, pp. 170-176. doi:10.1007/s00128-004-0564-0

[18] Z. Parveen, M. I. Khuhro and N. Kausar, "Evaluation of Multiple Pesticide Residues in Apples and Citrus Fruits, 1999-2001, Pakistan," Bulletin of Contamination Toxicology, Vol. 73, No. 2, 2004, pp. 312-318.

[19] N. Hassan, T. Anwar, S. Akhtar, et al., "Pesticide Residues Limits in Vegetables Growing around Karachi City, Pakistan," Journal of Experimental Zoology India, Vol. 10, No. 1, 2007, pp. 103-106. 